\title{
Comerciando con esclavos africanos desde Barcelona: Jaime Tintó Miralles (1770-1839)*
}

\author{
Martín Rodrigo y Alharilla ${ }^{1}$ \\ Universitat Pompeu Fabra \\ martin.rodrigo@upf.edu
}

RESUMEN: Este artículo tiene como objetivo la descripción y el análisis de la trayectoria vital del comerciante Jaime Tintó Miralles (1770-1839), un rico hombre de negocios, nacido y fallecido en Barcelona, aunque enriquecido en tierras americanas (en Mérida de Yucatán, primero, y en La Habana, después). Tras su segundo y definitivo regreso a Barcelona, en 1823, Tintó se convirtió en uno de los principales empresarios dedicados al comercio transatlántico de africanos esclavizados en dicha ciudad. Compaginó, además, su notable labor empresarial con una no menos notable actividad pública, ejerciendo como regidor del ayuntamiento de la capital catalana. El estudio de su trayectoria permitirá conocer y documentar mejor la vinculación de Barcelona con el comercio de esclavos hacia Cuba, asi como ofrecer nuevas pistas que ilustran cómo la dedicación a una actividad ilegal, la trata africana, permitió el enriquecimiento y el ascenso social de algunos individuos y de sus descendientes.

Palabras Clave: Barcelona; Cuba; África; comercio; esclavos; ilegalidad.

* Para la elaboración del presente artículo se han consultado documentos del Archivo Histórico de Protocolos Notariales de Barcelona, Barcelona (AHPB); Archivo General de Indias, Sevilla (AGI); Archivo Nacional de Cuba, La Habana (ANC); Archivo Histórico Nacional, Madrid (AHN); Archivo Histórico de la Oficina del Historiador de la Ciudad de La Habana, La Habana (OHCH-AH); Arxiu Nacional de Catalunya, Sant Cugat del Vallés, Barcelona (ANCat); y Archivo de la Corona de Aragón, Barcelona (ACA).

${ }^{1}$ ORCID iD: https://orcid.org/0000-0003-0423-7147.

Copyright: (C) 2021 CSIC. Este es un artículo de acceso abierto distribuido bajo los términos de una licencia de uso y distribución Creative Commons Reconocimiento 4.0 Internacional (CC-BY 4.0) 


\section{Barcelona and the African slave trade: Jaime Tintó Miralles (1770-1839)}

ABSTRACT: The article aims to describe and analyse the life of merchant Jaime Tintó Miralles (1770-1839), a rich businessman, who was born and died in Barcelona, but made his fortune in the Americas (first in Mérida de Yucatán, later in Havana). After his second and definitive return to Barcelona in 1823, Tinto became one of the main entrepreneurs dedicated to the transatlantic slave trade in this city. He combined his considerable business activity with a notable public role and was a councillor of Barcelona. The study of his career will help clarify the link between the capital of Catalonia and the slave trade in Cuba, as well as offering new clues to illustrate how dedication to an illegal activity, such as trafficking African people, allowed the enrichment and social promotion of some individuals and their families.

Key words: Barcelona; Cuba; Africa; trade; slaves; illegality.

CÓMO CITAR ESTE ARTÍCULO/CITATION: Rodrigo y Alharilla, Martín, «Comerciando con esclavos africanos desde Barcelona: Jaime Tintó Miralles (1770-1839)», Hispania, 81/267 (Madrid, 2021): 73-100. https://doi.org/10.3989/hispania.2021.003.

La implicación de algunos hombres de negocio catalanes en el comercio atlántico de africanos esclavizados hacia Cuba ha atraído la atención de diferentes investigadores ${ }^{2}$. En un artículo publicado en 1974 y dedicado a analizar las múltiples aristas de la relación entre la burguesía catalana y la esclavitud colonial, Jordi Maluquer de Motes señaló, por ejemplo, la implicación de diversos comerciantes de origen catalán en dicho tráfico, un tipo de negocio al que definió como «el más lucrativo de todos los lucrativos negocios que se podían emprender en Cuba». Destacó entonces dicho autor el nombre de algunos catalanes implicados en la trata africana, tanto de aquellos que operaban en La Habana (como Roque J. Llopart, Salvador Baró, Salvador Samá y Pancho Martí) como de los que lo hacían en Barcelona (tal que Maríano Flaquer y Juan Roig Jacas) ${ }^{3}$. También el historiador cubano Manuel Moreno Fraginals se refirió, en su monumental libro El Ingenio, a la relevante implicación de algunos catalanes en el comercio de esclavos en Cuba. Al identificar, por ejemplo, a los grandes «comerciantes negreros» de La Habana de 1820 señala a Pablo Samá Martí, Juan Samá Vilardell, Pancho Martí, Jaime Vilardebó e Isidro Inglada, así como a la firma Miró Pié y Cía. ${ }^{4}$ Unos años después fue Josep Maria Fradera quien publicó un artículo centrado monográficamente en el análisis de la

\footnotetext{
2 Este artículo es uno de los resultados del proyecto de investigación PID2019-105204GBI00 financiado por el Ministerio de Ciencia e Innovación/Agencia Estatal de Investigación.

${ }^{3}$ MALUQUER DE MOTES, 1974: 109.

${ }^{4}$ MORENO FRAGINALS, 1978, vol. 1: 268-269, 280 y 288.
} 
participación catalana en el tráfico de esclavos entre 1789 y 1845 . Así y según sus cálculos, el 24,7\% de los buques negreros de bandera española que entraron en La Habana durante los años de la trata legal (1789-1820) fueron embarcaciones catalanas. Un porcentaje que descendió ligeramente hasta situarse en el $23,04 \%$, en los primeros veinticinco años de la trata ilegal (1821-1845) .

Tras aquellos tres seminales estudios se han publicado otros trabajos sobre dicha temática. Artículos como el que publicó Josep Rovira en torno a la expedición a las costas africanas del bergantín Tellus, fletado a iniciativa de un rico hombre de negocios de Barcelona llamado Pedro Gil Babot ${ }^{6}$. También desde la historia local algunos autores han documentado la implicación en dicha actividad de determinados armadores, capitanes o marineros de diferentes localidades de la costa catalana como Vilanova i la Geltrú, Lloret de Mar o Vilassar de Mar, por citar algunos casos ${ }^{7}$.

Cabe igualmente destacar la publicación de dos nuevos libros, los cuales han aportado abundante y novedosa información sobre la participación de catalanes en la trata africana. El primero fue escrito por Gustau Nerín, quien ha puesto de relieve un fenómeno poco conocido antes de su investigación: la notable presencia de factores negreros españoles en las costas africanas. Y aunque su objeto de estudio fueron los españoles, en general, Nerín pudo dar también noticias de la presencia en África de diferentes responsables de factorías catalanes (como Domingo Mustich o Pablo Freixas, por citar un par de ejemplos $)^{8}$. El último de los libros publicados es el resultado de un trabajo coral, con ocho capítulos escritos por otros tantos autores, dedicados a analizar con cierto detalle diversas aristas de la compleja relación de Barcelona, en particular (y de Cataluña, en general) con el tráfico atlántico de esclavos. análisis que vienen a documentar lo que señala acertadamente Michael Zeuske en ese mismo libro, es decir, que «los catalanes consolidaron cada vez más su posición en la trata y la esclavitud, a lo largo de toda la isla de Cuba», y que «encontraron posibilidades de trabajo y de enriquecimiento en el ámbito de la trata de cuerpos humanos [especialmente] después de la abolición formal» de la misma, o sea, a partir de $1821^{10}$.

Vale la pena recordar que la firma, en 1817, de un tratado entre España y Gran Bretaña, había servido para ilegalizar el comercio transatlántico de africanos esclavizados así como para dar cobertura legal a la represión que la Royal Navy venía ejerciendo contra los buques negreros españoles. Así, a partir

\footnotetext{
${ }^{5}$ FRADERA, 1984.

${ }^{6}$ ROVIRA, 1984.

7 VIRELLA, 1990. SUST, 2016.

${ }^{8}$ NERÍN, 2015.

9 RODRIGO y CHAVIANO, 2017.

10 ZEUSKE, 2017.
} 
de 1821 ya no tendrían que haber llegado nuevos cautivos africanos a los dominios españoles en América. Sabemos, no obstante, que siguieron llegando, y que lo hicieron a gran escala. En tiempos de la trata ilegal (1821-1867) a Cuba llegaron, al menos, 543.882 nuevos esclavos ${ }^{11}$. Dicha isla se convirtió en el segundo territorio americano al que arribaron más cautivos africanos en aquel período, en tiempos de la abolición, sólo por detrás de Brasil. Fue precisamente en aquella ilegal actividad en la que participaron muchos hombres de mar y de negocio de la España peninsular, entre ellos muchos catalanes.

A pesar de que disponemos, de hecho, de una bibliografía cada vez más amplia sobre la participación catalana en aquel peculiar comercio, no es menos cierto que tenemos todavía importantes lagunas en nuestro conocimiento sobre dicho fenómeno. Nos falta identificar, por ejemplo, a algunos de sus principales protagonistas así como analizar sus respectivas trayectorias vitales. Este artículo obedece precisamente a la voluntad de cubrir una de esas lagunas. Pretendo describir y analizar, de hecho, la figura de uno de los principales comerciantes dedicados a la trata ilegal en Barcelona, a caballo de los años 1820 y 1830 . Un rico hombre de negocios, nacido y fallecido en la capital catalana, aunque enriquecido en tierras americanas, que se llamó Jaime Tintó Miralles (1770-1839). A través de su figura, me propongo desvelar nuevas facetas, hasta ahora escasamente conocidas, sobre la vinculación del puerto y de la ciudad de Barcelona con el comercio ilegal de esclavos africanos hacia Cuba, así como también señalar algunos de los legados que dicha vinculación dejaron en la capital catalana.

\section{Trazas de Una VIDa ITINERANTe (1770-1823)}

Jaime Tintó Miralles nació en Barcelona, probablemente en 1770. Cabría definirlo como un indiano, es decir, como un individuo que emigró al Nuevo Mundo con la intención de hacer las Américas y que consiguió realizar su objetivo. Tintó acabó instalándose en la ciudad de Mérida de Yucatán (al sur del virreinato de la Nueva España), donde ejerció como hombre de negocios. En dicha localidad mexicana se casó, el 17 de febrero de 1795, con la criolla María Loreto Guzmán Alvarado. El capital que Tintó había acumulado en aquella fecha, es decir, mientras estuvo soltero, se cifraba en 3.400 pesos fuertes. La novia no aportó dote alguna ${ }^{12}$. En Mérida de Yucatán nacieron, por cierto, las dos primeras hijas del matrimonio Tintó-Guzmán, llamadas Julia y Josefa, respectivamente.

\footnotetext{
11 ELTIS y FELIPE-GONZÁLEZ, 2020.

12 AHPB, Benito Lafont, manual de 1839 y 1840, 1839, fols. 110v-119r, 16.07.1839.
} 
Al cabo de un tiempo, la familia al completo optó por abandonar México para viajar hasta Barcelona, adonde arribaron en 1804. En la capital catalana residieron durante casi cuatro años hasta que, en el verano de 1808, partieron rumbo a Cádiz, huyendo del dominio francés. Fue precisamente en aquella portuaria ciudad andaluza donde nacieron los otros dos hijos del matrimonio, los hermanos Ana y Antonio Tintó Guzmán, quienes vieron por primera vez la luz en febrero de 1809 y en marzo de 1810, respectivamente. Mientras tanto, el patriarca Tintó disponía de un velero mercante de su propiedad, el bergantín General Blake, un buque dedicado al comercio marítimo entre España y América. Así, el 10 de mayo de 1810 Jaime Tintó solicitó permiso para marchar, en su barco y con su familia, hasta el mexicano puerto de Campeche y luego, desde allí, hasta Mérida de Yucatán, para atender sus negocios. Al pedir la preceptiva licencia Tintó quiso presentarse como un buen patriota que debía atender, sin embargo, sus negocios en tierras americanas. Según sus propias palabras, fue en «el mes de agosto de 1808 en que lograron salir de la esclavitud del tirano, abandonando su casa y propiedades [en Barcelona] desde cuyo tiempo han permanecido en esta ciudad [de Cádiz], contribuyendo como avecindados en ella con todos los auxilios que sus circunstancias les han permitido, para atender a la justa causa que la nación sostiene». Hubo cuatro hombres de negocio, residentes entonces en Cádiz, que certificaron la veracidad de las afirmaciones de Tintó, o sea, que «tiene hijos naturales de Mérida de Yucatán, que tiene allí fincas y casa de comercio, que el bergantín el General Blake es de la propiedad del mismo, que está cargando de su cuenta para el puerto de Campeche». Me refiero a Pablo Slover, Juan Aguilar, Joaquín Hano de la Vega y Juan Bautista Dotres ${ }^{13}$.

Este último era un destacado comerciante de Barcelona quien había optado, como Tintó, por refugiarse en Cádiz durante la ocupación napoleónica de la capital catalana; un hombre de negocios que comerciaba, desde Barcelona o desde Cádiz, con diferentes puertos de la América española. Cabe destacar que tiempo después, su hija Pilar Dotres Gibert acabaría casándose con Ramón de Llano Chávarri, un rico comerciante enriquecido, como Tintó, en México y que acabaría implicándose, también, en el tráfico atlántico de esclavos. Jaime Tintó Miralles obtuvo, finalmente, el preceptivo permiso para regresar a México el 22 de mayo de 1810. Lo hizo acompañado de toda su familia, a bordo de su bergantín General Blake ${ }^{14}$. Tintó aprovechó aquel viaje para acabar de liquidar sus intereses en Mérida de Yucatán. Luego partieron todos hasta La Habana, donde se avecindaron y donde él mismo empezó a girar como comerciante. Así, ya a la altura de 1820 el catalán Jaime Tintó desarrollaba desde la capital cubana una intensa actividad empresarial: se había especializado en recibir y

\footnotetext{
13 AGI, México, 2499A, núm. 62.

14 AGI, Arribadas, legajo 441, núm. 186.
}

Hispania, 2021, vol. LXXXI, n. ${ }^{\circ}$ 267, enero-abril, págs. 73-100, ISSN: 0018-2141, e-ISSN: 1988-8368 https://doi.org/10.3989/hispania.2021.003 
despachar buques para comerciar con los cercanos puertos mexicanos de Sisal y de Campeche (y, en ocasiones, también con otras ciudades portuarias novohispanas como Tabasco, Veracruz o Tampico). Desde la capital cubana y entre 1820 y 1822, Tintó despachó para dichos puntos las goletas Vigía, Camila, Dulce Nombre de María, Zaragozana y Vizcaína, los bergantines Bella Antonia, Teresa, Júpiter y Perla de Cataluña, el bergantín-polacra Scipión y las polacras Nuestra Señora del Mar y Suprema ${ }^{15}$. Algunos de aquellos buques realizaron no uno sino varios viajes entre Cuba y México. Aquella notable actividad desarrollada desde La Habana por Tintó coincidió con los últimos años de la guerra de independencia en tierras novohispanas y con el intenso tráfico de salida (de metales preciosos, de personas y de mercancías) que se registró entonces desde México hacia Cuba, del cual se pudo beneficiar Tintó. Un comercio registrado en tiempos de guerra y que fue tan intenso y lucrativo como arriesgado. Nuestro hombre llegó a perder algún buque, como el bergantín Júpiter, capturado por el corsario insurgente La Independencia ${ }^{16}$. En ese contexto, muchos fueron los peninsulares que optaron por abandonar el virreinato de la Nueva España durante la guerra, o que lo tuvieron que hacer una vez hubo acabado el conflicto, antes incluso de la aprobación de las dos leyes mexicanas de expulsión de españoles, de 1827 y de 1829. Estos peninsulares, en su mayoría, pasaron por Cuba antes de dirigirse a Europa ${ }^{17}$. El propio Tintó habilitó, también desde la capital cubana, diversas expediciones transatlánticas con destino al puerto de Cádiz, como las que tuvieron lugar en la goleta Irene o en los bergantines San José o San Buenaventura. Algunos de aquellos buques eran, por cierto, de su plena propiedad, como el bergantín-polacra Scipión o el bergantín San José18.

Uno de los hombres de negocio con quién Tintó competía entonces en La Habana era Pedro Martínez Pérez de Terán ${ }^{19}$. Dicho comerciante cántabro acreditaba una trayectoria similar a la del catalán Jaime Tintó: había emigrado primero a México donde había iniciado una próspera carrera como hombre de negocios; se había trasladado después a la capital cubana, donde se había

15 ANC, Protocolos de Marina de La Habana, 1820, tomo II, fols. 937v-938v, 06.06.1820; fols. 988r-990r, 21.10.1820; fols. 1130v-1131v, 23.12.1820; fols. 1147v-1149v, 29.12.1820; 1821, tomo I, fols. $290 \mathrm{v}-291 \mathrm{v}, 16.04 .1821$; fols. $452 \mathrm{v}-455 \mathrm{r}, 16.06 .1821$; tomo II, fols. $694 \mathrm{r}-696 \mathrm{r}$, 25.08.1821; fols. 1004r-1005v, 29.12.1821; 1822, tomo II, fols. $557 \mathrm{v}-559 \mathrm{v}, 03.08 .1822$; fols. $634 \mathrm{v}-635 \mathrm{v}, 29.08 .1822$; fols. $703 \mathrm{r}-705 \mathrm{r}$, 19.09.1822; fols. $808 \mathrm{v}-810 \mathrm{v}, 31.10 .1822$; fols. $885 \mathrm{v}-887 \mathrm{v}$, 02.12.1822; 1823, tomo I, fols. 93v-97r, 01.02.1823; fols. 239r-241r, 20.03.1823.

16 ANC, Protocolos de Marina de La Habana, 1822, tomo I, fols. 298v-299v, 17.04.1822.

17 SOLÀ, 1985. RUIZ DE GORDEJUELA, 2016a; 2016 b.

18 ANC, Protocolos de Marina de La Habana, 1822, tomo II, fols. 617r-618r, 26.08.1822; fols. $808 \mathrm{v}-810 \mathrm{v}, 31.10 .1822$; fols. $832 \mathrm{v}-833 \mathrm{r}, 09.11 .1822$; fols. $834 \mathrm{v}-835 \mathrm{v}, 11.11 .1822$, fols. $899 \mathrm{v}-901 \mathrm{r}, 30.12 .1822$.

19 CÓZAR, 2021.

Hispania, 2021, vol. LXXXI, n. ${ }^{\circ}$ 267, enero-abril, págs. 73-100, ISSN: 0018-2141, e-ISSN: 1988-8368 https://doi.org/10.3989/hispania.2021.003 
especializado en la explotación del tráfico mercantil y de personas entre la gran Antilla y México; y, también como Tintó, Martínez se había dedicado a habilitar, desde La Habana, diversas expediciones a algunos de los principales puertos peninsulares (a Santander y, sobre todo, a Cádiz). Uno y otro, Tintó y Martínez, vivieron en primera persona, durante sus años de residencia en La Habana, la intensa actividad registrada por dicha ciudad como puerto negrero. Lo pudieron vivir en una etapa de transición, o sea, en los últimos años del comercio legal de africanos esclavizados y en los primeros de su continuidad de forma ilegal y clandestina. Ambos empresarios acabarían abandonando la capital cubana para instalarse en los dos principales puertos de la España peninsular (Tintó en Barcelona y Martínez en Cádiz), donde uno y otro acabaron destacando por su actividad en el comercio ilegal de esclavos. El primero en regresar a la península fue Jaime Tintó, quien marchó de La Habana a mediados de 1823. Una nota publicada por el Diario de Barcelona en su edición del 28 de noviembre de 1823 nos indica que, en aquella fecha, Tintó vivía ya en la capital catalana y que ejercía como comerciante, especializado precisamente en remitir barcos a La Habana ${ }^{20}$.

\section{Operando en la trata desde Barcelona y Cádiz}

Instalado en la capital catalana, Tintó se dedicó a organizar expediciones negreras hacia Cuba. Las primeras las habilitó, eso sí, en el puerto de Cádiz. En julio de 1824 el embajador británico en Madrid informaba de «que se están equipando allí [en Cádiz] dos buques con el intento de emplearlos en el tráfico de negros, a saber la goleta Bella Dolores, maestre Dn. Antonio Guerrero y dueño don Jaime Tintó, de 170 toneladas; y el bergantín Alerta, maestre Dn. Antonio Echevarría y dueño Miguel Azopardo, destinado a Gibraltar y la Havana [sic], de 290 toneladas». Me parece significativo el testimonio ofrecido entonces por aquel diplomático británico, quien reprodujo entonces afirmaciones expresadas por nuestro hombre: «El dueño de uno de estos barcos (Tintó) declara públicamente ser la trata de esclavos el objeto de su viaje añadiendo que si de cuatro expediciones se salva una aun será ventajosa la operación $\rangle^{21}$. Lo cierto es que aquella fragata, Bella Dolores, culminó con éxito su expedición: salió de Cádiz el 13 de junio de 1824 rumbo a Madagascar, donde cargó más de doscientos africanos para llevarlos a Cuba y venderlos allí como esclavos. Tras haberlos desembarcado clandestinamente en alguna playa de la isla

\footnotetext{
${ }^{20}$ Diario de Barcelona, 28.11.1823: 4052.

${ }^{21}$ AHN, Estado, leg. 8015, doc. 44.
}

Hispania, 2021, vol. LXXXI, n. ${ }^{\circ}$ 267, enero-abril, págs. 73-100, ISSN: 0018-2141, e-ISSN: 1988-8368 https://doi.org/10.3989/hispania.2021.003 
arribó, finalmente, «en lastre» al puerto de La Habana el 13 de diciembre de aquel mismo año ${ }^{22}$.

Se conservan al menos trece cartas escritas en Barcelona por Tintó, entre diciembre de 1828 y el mismo mes de 1829 , y remitidas a uno de sus socios en La Habana, José Yrineo de Yrigoyen ${ }^{23}$. Ahora bien, aunque el receptor de las misivas era Yrigoyen, el verdadero socio de Tintó en La Habana era Joaquín Gómez Hano de la Vega (a quien se identifica prudentemente en las cartas como «J. G.»), un comerciante nacido en el pequeño pueblo de Hazas de Cesto, en Cantabria, el 20 de septiembre de $1776^{24}$. Hablar de Gómez es hablar de un individuo que sería, a la altura de 1836 y según Moreno Fraginals, la sexta fortuna de Cuba, y que integraba, junto a Gabriel Lombillo y a José Suárez Argudín, «el más importante triunvirato del contrabando de negros en [la isla de Cuba durante] la década de $1820 »^{25}$. La conservación de dichas cartas escritas por Jaime Tintó resulta un hecho excepcional en el contexto de una actividad ilegal, como era entonces la trata. Tal como se recogía precisamente en las instrucciones que el propio Yrigoyen acostumbraba a transmitir a los capitanes de sus buques dedicados a la trata: «No debe quedar a bordo ningún papel por pequeño que sea que haga relación al negocio. Todos los recogerá Vm. o los quemará», les ordenaba ${ }^{26}$.

De aquella correspondencia se deduce que Jaime Tintó llegó a habilitar en apenas quince meses cuatro expediciones negreras desde el puerto de Barcelona. La primera fue en el laúd Fernando VII, una embarcación que arribó con esclavos a Matanzas en diciembre de 1828 y cuyo capitán era Antonio Peña; la segunda, en el bergantín Nueva Amalia, que zarpó de la capital catalana rumbo a la Costa de Oro, capitaneada por Francisco Granell, el día de Navidad de 1828; la tercera en la goleta Ninfa (capitán, Melchor Vidal), que se hizo a la vela el 20 de febrero de 1829; y, por último, la cuarta expedición se realizó en el bergantín-goleta Catalana, cuyo capitán era Jaime Ricomá, que zarpó, también de Barcelona, el 2 de noviembre de 1829.

Además del propio Tintó hubo al menos otra empresa barcelonesa implicada en la financiación de aquellas expediciones: la firma Vilardaga Juliá y Reynals, que quiso invertir 6.500 pesos fuertes en la expedición del laúd Fernando VII, otros 13.000 pesos en la del bergantín Nueva Amalia y 10.000 pesos más en la expedición de la goleta Ninfa. Sus socios aportaron, en total, la respetable suma de 29.500 pesos fuertes. La participación de la casa Vilardaga

${ }^{22}$ House of Commons Parliamentary Papers..., 1825, fol. 130, Havannah, n. ${ }^{\circ} 93$, Henry T. Kilbee to Mr. Secretary Canning, 17.12.1824.

${ }^{23} \mathrm{OHCH}-\mathrm{AH}$, legajo 656.

${ }^{24}$ Agradezco dicha información a Íñigo Aguilar.

${ }^{25}$ MORENO FRAGINALS, 1978, vol. 1: 267-268.

${ }^{26} \mathrm{OHCH}-\mathrm{AH}$, legajo 508, 18. 
Julià y Reynals en aquellas tres expediciones se dio mientras dicha compañía solicitaba paralelamente una licencia (otorgada finalmente en marzo de 1830) o «privilegio exclusivo de S. M. [Fernando VII] para construir en Inglaterra un buque de vapor ${ }^{27}$. Este privilegio permitió la construcción del primer buque de vapor matriculado en Barcelona, el vapor Balear, cuyo primer capitán sería precisamente Francisco Granell. No hay duda de que aquella casa de comercio que se asoció con Jaime Tintó en la trata africana era una de las grandes firmas mercantiles de la capital catalana. De su iniciativa nació, por ejemplo, la Compañía Catalana de Vapor, creada en 1834 como precedente de la futura sociedad Navegación e Industria, firma fundadora de la Compañía Transmediterránea, en 1916. Uno de los socios de Vilardaga Juliá y Reynals, Juan Reynals, era, además, sobrino de un gran comerciante negrero de Santiago de Chile y de Buenos Aires, a finales del siglo XVIII y principios del siglo XIX, llamado Olaguer Reynals.

Una de las funciones que correspondían a Jaime Tintó en Barcelona era la de supervisar la construcción de nuevas embarcaciones, encargadas expresamente para la trata africana. Así hizo con el bergantín Nueva Amalia y con la goleta Ninfa, de los que decía: «Se ha puesto todo esmero en la construcción de los dos buques, el bergantín es largo, ermoso y debe, según sus cortes, ser de lera marcha superior, la goleta también es de buena pieza y se ha probado en su benir de Areñs donde se construyó pero no es tan de mi gusto como el bergn. porque no me fue posible estar a la mira de la obra pero es buque sólido y de pieza [sic]». Su confianza en el Nueva Amalia aumentó el mismo día que dicho buque inició su primera expedición hacia la Costa de Oro. Según Tintó le confiara a su socio Gómez: «El día de la salida probé el buque en todas direcciones y puedo asegurarle que es de primera marcha superior y espero que cuando llegue [a Cuba] baya vm. a bordo a ver una cosa buena $\rangle^{28}$. Desde la capital catalana, Jaime Tintó se hacía igualmente cargo de la selección de los aseguradores de las expediciones, radicados tanto en su ciudad natal como en las portuarias ciudades de La Coruña y de Cádiz. Cabe tener presente que se trataba de un comercio ilegal y que, por lo tanto, la confianza entre aseguradores y asegurados debía ser total. Tal como informara, por ejemplo, a sus socios de La Habana: «En quanto a los aseguradores hasta el día han pagado puntualmente. Para ello se escogen los sugetos de moral seguridad». Otro de sus cometidos consistía en seleccionar a los capitanes. A Melchor Vidal, por ejemplo, lo eligió por ser «sugeto inteligente del mayor tino, onradez y conocimiento del punto a donde ha hir, y estoy seguro que quando vm. lo bea [le decía a Yrigoyen] encontrará en él un sujeto recomendable y mejor que quantos hemos tenido [sic]». Del experimentado capitán Jaime Ricomá decía, por otro lado, que era «muy

\footnotetext{
27 ANCat, Fondo Castañer, 02.04.23 (2).

${ }^{28} \mathrm{OHCH}, \mathrm{AH}$, legajo 656, cartas de Jaime Tintó (Barcelona) de 17.12.1828 y 05.01.1829.
} 
hombre de bien como berá Vm. a su tiempo», añadiendo que «la oficialidad y marinería [del bergantín-goleta Catalana] es de lo mejor, el buque es nuebo y conocido por de $\left.1 .^{\mathrm{a}}[\mathrm{sic}]\right\rangle^{29}$. Aquel velero capitaneado por Ricomá arribó sin problemas y en lastre a La Habana, en mayo de 1830, tras haber descargado en algún punto de la isla su humana mercancía de africanos esclavizados. No sirvieron de nada, entonces, las denuncias de los funcionarios británicos desplazados a la capital cubana ante la complicidad de unas autoridades militares españolas que dieron rápidamente carpetazo al asunto sin molestarse en inves$\operatorname{tigar}^{30}$. Cabe añadir, por cierto, que Tintó indicó siempre a los capitanes que trabajaron a sus órdenes que intentasen esclavizar sólo a hombres africanos, limitando la compra de mujeres al mínimo imprescindible. Tal como quiso recordar en una carta dirigida al habanero José Yrineo de Yrigoyen, socio de Joaquín Gómez en dichos menesteres: «En todas las Ynstrucciones dadas a los capitanes habrá $\mathrm{Vm}$. visto que solo les poníamos una sexta parte de $\mathrm{H}$ [hembras], pero opinamos que no es fácil conseguirlo, y es el motivo que llevan mayor número», consignaba Tintó a finales de marzo de $1830^{31}$.

Sabemos que el comerciante barcelonés Cristóbal Roig y Vidal había intentado, sin éxito, fundar una factoría esclavista en Madagascar. Y ahora sabemos también que Jaime Tintó estuvo igualmente valorando la posibilidad de establecer una factoría propia, en algún punto de la costa africana. Aquel proyecto, planteado en el verano de 1829, parece haber sido, en realidad, una propuesta de la casa Vilardaga, Julià y Reynals y el encargado de su materialización parece haber sido el capitán Francisco Granell. Aun así, las diferencias de Tintó con dicha sociedad le animaron a descartar ese nuevo negocio. Según informaría, en el otoño de aquel año, a Joaquín Gómez: «Esperaba la llegada de Granell para tratar y ver si era combeniente el Establecimiento en la C [osta] para los consabidos negocios, pero hoy pienso de otra manera respeto a que en adelante haremos nuestras espediciones [sic] sin que haya más interesados que Vd., los amigos de Cádiz y yo, pues no quiero reclamos ni que se nos aten a Vm. ni a mí las manos para hacer las que nos dé la gana». Unos meses después, en marzo de 1830, Tintó insistía en su nula disposición a implicarse en dicha iniciativa: «Sobre el proyecto del Establecimiento en la C. [Costa de África] ahunque [sic] nosotros estamos en que no se ponga por las razones fundadas de Vm. y seguiremos con los buques que tenemos, tomando otras precauciones porque no sean tan largas las demoras $»\rangle^{32}$.

${ }^{29} \mathrm{OHCH}-\mathrm{AH}$, legajo 656, cartas de Jaime Tintó (Barcelona) de 05.01.1829 y 11.11.1829.

30 AHN, Estado, 8016, 27, 1830. Bergantín Catalana. Capitán D. Jayme Ricoma.

31 SOSA, 1998: 89.

32 OHCH-AH, legajo 656, carta de Jaime Tintó (Barcelona) de 11.11.1829. También SOSA, 1998: 104. 
En Barcelona, a Jaime Tintó le correspondía también comprar y embarcar las mercancías necesarias para la expedición. Algunas debían servir para ser canjeadas, en África, a cambio de los cautivos, mientras que otras debían dedicarse para la ulterior manutención de los mismos, durante la travesía transoceánica. Se encargaba, por lo tanto, de preparar la mayor parte de la llamada «factura» de las expediciones. En ese sentido, a Tintó le tocaba igualmente entregar al capitán de cada expedición dinero en efectivo. Para el bergantín Nueva Amalia, por ejemplo, adquirió abundantes mercancías que se debían trocar después, en Ajudá y con Francisco Félix de Souza, por 450 esclavos $^{33}$. Lo hizo, eso sí, siguiendo las recomendaciones de Joaquín Gómez, a quien confiaba:

El buque, cargamto., tripulación, víveres y aguada, todo es sobrado. La factura importará 31 [mil] de su costo sin gasto alguno y solo de aguada lleba 130 pipas debajo de cubierta, de suerte que esta expedición ba en un todo como Vm. quiere.

Y respecto a la factura del bergantín-goleta Catalana, Tintó dejó escrito: «Como el género ha subido y la expedición es para 370 lros. [esclavos] lleva de factura 150 mangotes de tabaco Brasil, 150 barriles Aguardte. de 21 grados, 31 [ilegible] de géneros comprados a precios muy bajos y $15.400 \$$ en efectivo, de suerte que el total de la factura se aproximará a 21 [mil] \$ y según calculo su costo total echo a la vela será el de $34 »$ mil pesos $^{34}$.

Tras zarpar de Barcelona, aquellos buques preparados por Tintó recalaban tanto en Gibraltar como en Cádiz, donde completaban la susodicha factura. Llama la atención que fuese en un territorio, como el peñón de Gibraltar, sujeto a la soberanía del Reino Unido (de ese mismo Reino Unido que tanto perseguía el comercio de esclavos), donde se acabasen de habilitar las embarcaciones de la trata. Las cosas parecen haber cambiado, sin embargo, a partir de agosto de 1829, tal como deploraba Tintó: «Como en Gibraltar se han dictado unas órdenes las más severas para prohibir el despacho de todo buque de indicios de ser para estos viajes, no hay absolutamente allí quien quiera hacerse cargo del despacho». Al menos hasta aquella fecha hubo, sin embargo, comerciantes llanitos implicados en la trata.

Una de aquellas expediciones armadas en la capital catalana por Jaime Tintó llevó a bordo a un pasajero singular. Me refiero al joven científico valenciano Marcelino Andrés y Andrés, quien se había mudado a Barcelona, en 1826, para estudiar medicina. En Barcelona, Marcelino Andrés conoció al joven

${ }^{33}$ La portuaria ciudad de Ajudá (también conocida como Ouidah y Whydah) está situada en la actual República de Benín, en la costa atlántica africana. Francisco Félix de Souza, también conocido como Cha-chá, fue el más importante negrero de dicha ciudad durante el siglo XIX. Sobre su trayectoria, véase LAW, 2017: 155-188.

${ }^{34} \mathrm{OHCH}-\mathrm{AH}$, legajo 656, cartas de Jaime Tintó (Barcelona) de 17.12.1828 y 11.11.1829. 
naturalista Mariano de la Paz Graells, con quien hablaba frecuentemente de la posibilidad de conocer y estudiar la flora del continente africano. El cierre temporal de la barcelonesa Academia de Medicina, en 1830, dio alas al joven estudiante valenciano para poder cumplir su sueño. Se presentó un día en casa de su amigo Graells y le dijo:

Yo voy a viajar, si quieres venir conmigo podemos llevar a cabo nuestras soñadas expediciones. Una excursión al cabo de Buena Esperanza sería un hermoso paseo. No creas que se trata de ningún proyecto imposible para nosotros, he aquí mi plan. Nos embarcamos en un barco negrero y nuestro viaje al África todavía nos puede proporcionar alguna ganancia. Cuando estemos allí se verá lo que más nos conviene.

Quien acabaría publicando, un siglo después, el testimonio de los viajes del joven naturalista Marcelino Andrés, el fraile agustino Agustín Jesús Barreiro, es quien relató la respuesta del interpelado: «No fue posible a Graells acceder a los deseos de su amigo por motivos muy racionales, y comprendiéndolo éste así determinó lanzarse sólo a la aventura». En efecto, tal como acabaría escribiendo de su puño y letra el propio Marcelino Andrés, al principio de un interesante libro de viajes: «Salimos el 13 de noviembre de 1830 del puerto de Barcelona con el bergantín Nueva Amalia y llegamos a las costas de Oro en Guinea a los cuarenta y cinco días de navegación». Aquel intrépido viajero apenas tenía entonces, por cierto, veintitrés años. Allí se quedó el joven valenciano durante un tiempo, trabajando como médico personal del rey de Dahomey. Mientras tanto, en Barcelona, los conocidos del joven naturalista estaban preocupados por su suerte. Así lo relató en su día el fraile Agustín J. Barreiro:

Transcurrieron muchos meses sin que Marcelino diese cuenta de su vida. Vagas noticias traídas por marinos que habían navegado en aguas africanas hicieron sabedores a sus amigos de las terribles pestes que habían atacado a los blancos empleados en los barcos negreros [...]. Al fin se recibió una carta del viajero, fechada en Bomsi, capital del reino de Dahomey, dándoles noticias de sus andanzas y haciéndoles saber que sus conocimientos del arte de curar le habían conquistado la plaza del médico del Dadá o monarca de aquella región.

Aunque pronto alcanzó, como se ve, una ocupación más que aceptable, Marcelino Andrés se había comprometido previamente con el capitán del bergantín Nueva Amalia a trabajar como médico en la siguiente expedición negrera de dicho buque. Y así lo acabó haciendo, como relatara también el fraile Barreiro:

A pesar de la fortuna que asistió a Marcelino en Dahomey, por su cargo de médico del jefe supremo, no pudo sustraerse al compromiso contraído con el capitán del Nueva Amalia, viéndose en la precisión de reembarcar para cumplir sus deberes profesionales durante la travesía de dicho barco, rumbo a Cuba. 
Desempeñada esta misión, recabó Marcelino su libertad y siete días después de su arribo a la mencionada isla tomó pasaje en el bergantín-goleta Catalana y se trasladó de nuevo a las costas de Guinea desembarcando en Aquitá, donde le esperaba su fiel amigo D. Antonio Constantín ${ }^{35}$.

Aunque no pretendo profundizar en la labor científica del joven Marcelino Andrés, valga recordar que Leida Fernández Prieto le ha definido como «el arquetipo del naturalista interesado en coleccionar, identificar y difundir un saber sobre la utilidad de las plantas afines a la botánica económica y médica» y que dicha autora ha destacado que su estancia en África «le permitió confeccionar un herbario con 6.000 plantas». Una colección que intentó enviar a España, aunque sin éxito ${ }^{36}$.

El ejemplo de Marcelino Andrés sirve para ver hasta qué punto podía entonces resultar fácil a cualquier vecino de Barcelona embarcarse en un buque negrero, rumbo a África, pese a la supuesta clandestinidad de la trata; sirve también para apreciar hasta qué punto el destino real (no el oficial) de los buques armados desde Barcelona por Tintó era bien conocido en diversos medios de la ciudad; sirve igualmente para darse cuenta de que, a la altura de 1830, la mucha o poca comunicación registrada entre Barcelona y los diversos puertos de las costas del África subsahariana se producía (vía cartas o vía informaciones orales) únicamente a través de los buques negreros y de sus tripulaciones; y sirve, por último, para ilustrar cómo la posibilidad de trabajar como facultativo en alguna expedición negrera era una salida profesional tan válida como cualquier otra (insisto, pese a la aparente clandestinidad de dicha actividad) para los jóvenes médicos egresados de las diferentes escuelas de medicina peninsulares, como la de Barcelona.

Volviendo a las cartas manuscritas de Jaime Tintó, cabe señalar que el historiador cubano Enrique Sosa Rodríguez consultó en su día aquellas trece misivas $\mathrm{y}$, además, muchas otras cartas escritas igualmente por dicho comerciante (hasta un total de ochenta y una), fechadas entre octubre de 1827 y el mismo mes de 1836, a partir de las cuales elaboró un interesante librito ${ }^{37}$. Pudo así identificar claramente los tres vértices de un triángulo o red dedicada al tráfico de africanos esclavizados con destino a los campos y ciudades de Cuba: La Habana, Barcelona y Cádiz. En el nodo gaditano de dicha red cabe destacar la presencia de tres hombres de negocio a quienes Tintó identificaba en sus cartas como «los amigos de Cádiz». Me refiero a José de la Vega, José de Hano Sierra y Francisco Antonio de la Concha. Cabe recordar que el primero había sido uno de los testigos que habían avalado, en mayo de 1810, la petición de Tintó de

\footnotetext{
${ }^{35}$ Relación del viaje..., 1933.

36 FERNÁNDEZ, 2018: 305-308.

37 SOSA, 1998.
} 
salir de Cádiz rumbo a México y que tanto el primero como el segundo fueron, probablemente, familiares directos de Gómez. Sosa caracterizó a Jaime Tintó como el «organizador de las expediciones desde Europa, para lo cual habilitó una verdadera flota negrera que comprendió, además de una fragata capturada por los ingleses [la Veloz Pasajera], bergantines, goletas, bergantines-goletas y laúdes, casi todos construidos en Europa: en Barcelona y las islas Baleares». Dicho autor concluye que fueron «un total de quince barcos navegando, sobre todo, entre 1829 y 1831, algunos de ellos vinculados, al menos, con dos viajes a África» y recoge sus nombres: la fragata Veloz Pasajera, los bergantines Reina Amalia, Nueva Amalia, Águila y Reemplazo, los bergantines-goleta Catalana y Manzanares, la goleta Ninfa y los laúdes Fortuna y Fernando VII, además de los también veleros Semiramis, Dichosa, San Fernando y Moctezuma y del buque Andaluz, propiedad del gaditano Francisco Antonio de la Concha $^{38}$.

Las cartas que Jaime Tintó envió a José Yrineo de Yrigoyen ofrecen interesante información sobre el mundo del tráfico atlántico de esclavos pocos años después de su ilegalización. En marzo de 1831, por ejemplo, Tintó escribía a Yrigoyen que las relaciones entre negreros funcionaban a modo de «acuerdos entre caballeros» pues «en esta clase de negocios todo es bajo palabra y de buena fe» ${ }^{39}$. Aquella misiva vino motivada, por cierto, por las públicas discrepancias de la sociedad de Jaime Tintó e Hijo con otra casa de comercio también de Barcelona, la firma Vilardaga Julià y Reynals. También en la última de sus ochenta y una cartas, fechada en octubre de 1836, Tintó seguía caracterizando a los socios de aquella empresa como «díscolos y miserables» así como «ridículos», a la par que afirmaba seguir estando harto «por sus continuos reclamos»y arrepentirse por haberlos incluido en las «expediciones» a las costas africanas, porque «me han consumido el alma con reclamos y observaciones propias de la mezquindad de esta clase de gentes». Quien intentó mediar en aquella agria disputa entre las firmas Jaime Tintó e Hijo y Vilardaga Julià y Reynals fue un comerciante, también de Barcelona, dedicado igualmente a la trata africana llamado Domingo Martorell Guitart; un hombre de negocios nacido en Calella que antes había girado como comerciante en La Habana, donde se había dedicado al tráfico atlántico de esclavos $^{40}$. A su regreso, a Barcelona, Domingo Martorell fundó una empresa de comercio llamada Martorell Hermanos.

Tal como hiciera la sociedad Vilardaga Julià y Reynals, sabemos que hubo otros hombres de negocio de Barcelona que aportaron parte de sus capitales para financiar algunas de las expediciones a las costas africanas armadas por Tintó. Su correspondencia conservada en Cuba apenas ofrece pistas, sin

\footnotetext{
38 SOSA, 1998: 2, 43.

39 SOSA, 1998: 29-30.

40 ANC, Tribunal de Comercio, legajo 513 (29).
} 
embargo, para conocer quienes fueron. En una carta, fechada el 4 de marzo de 1831, le confiaba Tintó a Yrigoyen: «Quando [sic] escribimos a Vd. contábamos con un interesado aquí [en Barcelona] que nos ofreció tomar 6.000 \$ [pesos fuertes o duros] y a la última ora [sic] nos salió con que no quería por las noticias de buques apresados en aquella época, y porque sabía por los que vinieron a bordo que el Aguila no era buque de $10^{\text {a }}$ marcha» ${ }^{41}$. Sabemos que uno de los individuos que financiaron sus expediciones, en su caso desde su Vilanova i la Geltrú natal, fue Pelegrín Marqués Torrents. Se trata de un indiano enriquecido como comerciante en La Habana, donde llegó a ejercer como socio director de la casa Marqués Ferrer y Cía., junto a su paisano, Gregorio Ferrer Soler. A su regreso a Cataluña, ambos individuos (tanto Marqués como Ferrer) mantuvieron una intensa actividad empresarial que les hizo participar, por ejemplo, en la fundación de una empresa textil en su localidad natal, la famosa Fábrica de la Rambla. Los dos llevaron también a cabo diferentes negocios relacionados con Cuba, entre los que cabe destacar su participación en diversas expediciones negreras, algunas en sociedad con Jaime Tintó y otras no. Raimon Soler ha encontrado en la correspondencia de Gregorio Ferrer evidencias de la dedicación de ambos al comercio ilegal de esclavos, al menos hasta la firma del segundo tratado hispano-británico de persecución de dicha actividad, en junio de 1835. En una carta que dirigió en febrero de 1834 a La Habana, a la atención de la casa Font Gumá y Cía., consignaba: «Me ha sido de mucha satisfacción la feliz llegada del bergantín A de B, y que a pesar de haber fallecido Ms. [muchos], serán reintegrados de todo su alcance». $\mathrm{Y}$ en otra misiva que les escribió dos años después, en marzo de 1836, les confiaba: "A su tiempo comuniqué al amigo D. Pelegrín Marqués el apresamiento de los 4 buques por los ingleses, lo que según Vs. dicen se han anticipado ha dar cumplimiento al nuevo tratado; que con arreglo a él, bien pocos serán los que escaparán de sus uñas, por lo que considero deve olvidarse esta clase de comercio por los muchos riesgos que le amenazan $[$ sic $]\rangle^{42}$.

\section{La Sociedad Jaime Tintó e HiJo (1830-1833)}

Mientras Tintó seguía intensamente dedicado a habilitar expediciones negreras desde Barcelona, tuvo lugar la muerte de su mujer, la mexicana María Loreto Guzmán. Fue en 1829. En la medida que el enlace matrimonial entre ambos se había realizado años atrás, en 1795, en el virreinato de la Nueva España, donde regían las leyes de Castilla, el viudo Tintó tuvo entonces que repartir la porción de los bienes gananciales correspondientes a su mujer entre

\footnotetext{
41 SOSA, 1998: 41.

${ }^{42}$ SOLER, 2002: 93.
} 
su único hijo varón (Antonio) y sus tres hijas (Julia, Josefa y Ana), en cuatro partes iguales. Aunque el patriarca de la familia Tintó no quiso escriturar el inventario privado de los bienes de su sociedad conyugal, calculo que su fortuna, en el momento del fallecimiento de su mujer, debía situarse en unos 55.600 pesos fuertes (sin tener en cuenta los cuantiosos «créditos de dudoso cobro», los cuales sumaban otros 13.411 pesos más). Lo cierto es que cada uno de los cuatro hijos de la difunta Loreto Guzmán recibió entonces, en 1829, su preceptiva hijuela, por valor de 5.227 pesos. Dicho esto, quiero suponer que para evitar que la muerte de su esposa significase una mayor descapitalización en sus negocios, Jaime Tintó Miralles optó por crear inmediatamente una sociedad mercantil con su único hijo varón, la firma Jaime Tintó e Hijo. Lo hizo con efectos del 1 de enero de 1830 si bien no acudió a escriturar la preceptiva contrata social hasta seis meses después, el 28 de junio. El capital social de la firma Jaime Tintó e Hijo se cifró en 36.600 duros o pesos fuertes (equivalentes a 183.000 pesetas), de los cuales el joven Antonio Tintó Guzmán interesaba 5.227 duros (o sea, toda su porción hereditaria) y su padre aportaba el resto. Los dos socios hicieron sus aportaciones «en efectos, créditos, seguros y dinero efectivo, según consta en el balance celebrado para el efecto con fecha 31 de diciembre de 1829 a satisfacción de ambas partes». En uno de los pactos de la escritura social se hablaba, por cierto, de unos créditos de dudoso cobro (flecos provenientes, tal vez, de alguna o de varias expediciones fallidas a la costa de África), por un importe total de 13.912 duros más; una cantidad que debería incrementar el capital de la compañía en el eventual caso de que se pudiesen recuperar ${ }^{43}$.

El hecho de no haber escriturado la contrata social hasta seis meses después de la supuesta constitución de dicha compañía no fue, sin embargo, la única irregularidad registrada. Tampoco la más importante. Al crearse, presuntamente, la susodicha firma Jaime Tintó e Hijo (en enero de 1830), su hijo Antonio Tintó Guzmán apenas sumaba diecinueve años. Era, por lo tanto, menor de edad civil y, como tal, estaba incapacitado legalmente para intervenir en contrata de sociedad alguna. Aun así, la irregular creación de la firma Jaime Tintó e Hijo permitió al patriarca Jaime Tintó Miralles seguir utilizando la hijuela correspondiente a su único hijo varón para seguir financiando sus diversos negocios. No pudo o no quiso hacer lo mismo con sus tres hijas, de manera que la obligada entrega a las mismas de sus hijuelas correspondientes debió significar una merma en la capacidad financiera del negrero Tintó. De todas formas, en marzo de 1833 Jaime Tintó Miralles se vio obligado a anular anticipadamente el contrato de sociedad de la casa Jaime Tintó e Hijo, ante las dudas suscitadas precisamente por la minoría de edad de su único hijo varón y socio ${ }^{44}$.

\footnotetext{
43 AHPB, José Elias y Cebrià, manual de 1830 y 1831, 1830, 28.06.1830, fols. 46r-48r.

${ }^{44}$ AHPB, Benito Lafont, manual de 1839 y 1840, 1839, fols. 110v-119r, 16.07.1839.
} 
Afirma Enrique Sosa que fue a partir de mediados de 1831 cuando empezaron a vender (casi siempre en La Habana) los diversos veleros que habían conformado la flota Tintó. Unas ventas que, según dicho autor, se debieron más a las decisiones del tándem habanero Joaquín Gómez-José Yrineo de Yrigoyen («al considerar que no era conveniente tener tantos barcos») que a la apuesta del propio comerciante barcelonés. Tintó, de hecho, se vanagloriaba, todavía en octubre de 1832 y tras la exitosa expedición del bergantín Águila, de su fortuna en ese negocio. Según sus palabras, fueron «13 [los barcos] despachados por el socio dn. Jayme [Tintó] sin haber perdido ni uno». Desgranando las susodichas cartas, escritas por Tintó y conservadas en La Habana, Enrique Sosa ha podido reconstruir, al menos, dieciocho expediciones armadas por el clan GómezTintó en apenas seis años: una primera en 1827 (Dichosa), seis en 1828 (¿Nueva? Amalia, San Fernando, Veloz Pasajera, Fernando VII y Dichosa), otras cuatro en 1829 (Nueva Amalia, Catalana, Semiramis y Ninfa), cinco más en 1830 (Veloz Pasajera, Manzanares, Fortuna, Nueva Amalia y Águila), dos más en 1831 (Reina Amalia y Águila) y una última expedición en 1833 (Reemplazo) $^{45}$. De ser cierta la información que recoge Enrique Sosa, la implicación de Jaime Tintó en el tráfico ilegal de africanos esclavizados desaparecería en 1833. Es más, el fin de su actividad como comerciante vinculado a la trata coincide con unos momentos de cambio en la arquitectura de los buques negreros. Hasta entonces, Jaime Tintó había operado con veleros construidos, en su mayoría, en alguna localidad catalana, como Arenys de Mar, o, en algún caso, en Mahón. Cada vez más, sin embargo, los comerciantes habaneros dedicados a la trata preferían disponer de buques construidos en los astilleros estadounidenses (singularmente, veleros fabricados en Baltimore), a los que consideraban más rápidos $\mathrm{y}$, por lo tanto, mejor preparados para escapar de una eventual persecución por buques de la Royal Navy. Gómez y Tintó mostraron, en aquel tema, opiniones distintas, pues el segundo prefería los buques construidos en España. Fue entonces, en aquel contexto, cuando se acabó de producir la retracción de Tintó en la trata africana.

Sea como fuere, desde 1833 y hasta su fallecimiento, acaecido en 1839, Jaime Tintó mantendría, sin embargo, su vinculación al comercio legal de mercancías, especialmente con la isla de Cuba. Y es que la actividad mercantil de Jaime Tintó Miralles (y de su firma familiar, Jaime Tintó e Hijo) no se limitaba al tráfico de africanos esclavizados. Abundan, de hecho, las noticias sobre su actividad como consignatario de buques que conectaban Barcelona con diferentes puertos americanos y, sobre todo, con el puerto de La Habana, desde su definitiva instalación en Barcelona, en 1823. Con frecuencia, esa dedicación al comercio marítimo legal con Cuba era complementaria de su implicación en la

\footnotetext{
${ }^{45}$ SOSA, 1998: 43-44 y 52.
} 
trata ilegal y se producía en los mismos buques negreros de su flota y con los mismos capitanes. Así, la inversión en commodities coloniales compradas en Cuba (en azúcar, por ejemplo) para su ulterior venta en Barcelona puede verse como una de las formas utilizadas por Tintó para transferir a la capital catalana las ganancias derivadas de la trata ${ }^{46}$. Otra de las actividades en qué la firma Jaime Tintó e Hijo utilizó sus barcos fue para el transporte de prisioneros y de confinados políticos desde la España peninsular hasta distintos y distantes puntos insulares. Una actividad peculiar que requería una previa contratación con las autoridades de la Marina real. Tintó recibió el encargo, por ejemplo, de llevar hasta las islas Canarias a algunos de los liberales radicales acusados de haber promovido las bullangues de Barcelona del 4 y 5 de enero de 1836, incluyendo el asesinato extrajudicial de numerosos prisioneros carlistas. Uno de aquellos diecinueve deportados fue, por cierto, el famoso conspirador Eugenio de Aviraneta, quien protestó airadamente por el trato recibido en un barco de la flota Tintó ${ }^{47}$. Otra de aquellas contratas la firmaría el propio Tintó el 28 de mayo de 1836 e implicaría el traslado en su bergantín Lancero de varias decenas de deportados a la isla de Cuba desde los puertos de Barcelona y de Tarragona $^{48}$. Jaime Tintó no fue, por cierto, el único comerciante negrero de Barcelona que acabó dedicando sus buques al transporte de deportados: también lo hicieron sus antiguos socios Vilardaga Julià y Reynals (con su goleta Ninfa, por ejemplo ${ }^{49}$.

\section{Jaime Tintó Miralles, destacado contribuyente y concejal del Ayunta- MiENTO DE BARCELONA}

Jaime Tintó desarrolló una intensa actividad pública, especialmente en los últimos años del reinado de Fernando VII y en los primeros de la regencia de la reina María Cristina. Su reconocida dedicación a una actividad ilegal, como era la trata atlántica, no parece haber sido obstáculo para acabar alcanzando diversos cargos acordes a su fortuna y estatus: fue vocal, por ejemplo, de la

46 «De la Habana y del lazareto de Mahón, donde hizo la cuarentena, en 64 días el bergantín-goleta la Catalana, de 79 toneladas, su capitán Don Jaime Ricomà, con azúcar a Jaime Tintó e Hijo», véase Diario de Barcelona, 25.07.1830: 1747.

47 La Revista Española, Madrid, 21.06.1836: 3. La lista completa de los 19 deportados en la tesis doctoral de Juan Luis Bachero: La neutralización del adversario político. La deportación en la España del siglo XIX, Universitat Jaume I, 2017: 143-144, consultada por gentileza del autor.

48 ANC, Reales Órdenes y Cédulas, leg. 99, exp. 115.

49 ANC, Reales Órdenes y Cédulas, leg. 99, exp. 95. Sobre la actividad de Jaime Tintó e Hijo (y también de Vilardaga Julià y Reynals) en el transporte de deportados, véase ACA, Real Audiencia, Tribunal de Comercio, exp. 786. 
Real Junta de Comercio de Cataluña (desde, al menos, enero de 1831); y merced a su condición de representante de dicha entidad, acabaría incorporándose, en mayo de 1835, también como vocal de la Junta Provincial de Sanidad de Barcelona ${ }^{50}$. Y cuando poco después acabe estallando la guerra civil o carlista, el liberal Jaime Tintó Miralles no dudó en incorporarse a la Guardia Nacional, integrándose en el Escuadrón de Lanceros Voluntarios de Isabel II de la capital catalana, un cuerpo de milicias que también ayudó a financiar. Ítem más, consiguió que su hijo Antonio Tintó Guzmán, quien acababa de alcanzar la mayoría de edad, asumiese el cargo de Primer Ayudante (en funciones de Secretario) de dicho cuerpo ${ }^{51}$.

La proyección pública y política de Jaime Tintó dio un salto cualitativo en febrero de 1833 cuando fue elegido como uno de los quince concejales o regidores del Ayuntamiento de Barcelona en las que serían, a la postre, las últimas elecciones municipales del reinado de Fernando VII ${ }^{52}$. No hay que olvidar que las condiciones que reglamentaron dichas elecciones indicaban que, en cada municipio, sólo gozaban del derecho de sufragio activo y pasivo los mayores contribuyentes, entre los de su clase ${ }^{53}$. Su elección, por lo tanto, como regidor del principal ayuntamiento catalán indica que se hallaba, ya en aquella fecha, entre los más ricos comerciantes de la plaza. Entre las múltiples obligaciones derivadas de su condición de concejal del Ayuntamiento de la ciudad más poblada de Cataluña quiero destacar la responsabilidad de Tintó como tesorero de la junta encargada del ensanche de la Real Plaza de Palacio de Barcelona, es decir, de la comisión municipal encargada de materializar el derribo de una parte de la antigua muralla de mar de la capital catalana. Fue en el escritorio de su casa de comercio (o sea, en su domicilio sito en el número 3 de la calle Escudellers Blanchs) donde tuvo lugar la preceptiva subasta de la que salió el contratista encargado del susodicho derribo ${ }^{54}$.

En el otoño de 1835 volvió a haber elecciones municipales. En el listado de electores que hizo público el ayuntamiento de Barcelona, recogiendo los principales contribuyentes de la ciudad, aparece nuevamente Jaime Tintó, quien sabemos que se situaba entonces entre los cincuenta hombres más ricos de la capital catalana. No cabe duda de que gracias a su actividad empresarial, en general, y gracias a su implicación en el tráfico atlántico de africanos esclavizados, en particular, el barcelonés Jaime Tintó Miralles había protagonizado

50 Diario de Barcelona, 02.02.1831: 250-251 y 25.05.1835: 1.152-1.153.

${ }^{51}$ Diario de Barcelona, 20.01.1836: 158-159.

52 Diario de Barcelona, 25.02.1833: 445.

53 Diario de Barcelona, 12.02.1833: 337-339: «Estas elecciones se harán por los actuales ayuntamientos, juntamente con igual número de vecinos al de los miembros que hoy componen aquellas corporaciones, que serán los mayores contribuyentes de cualquier tipo de impuesto».

${ }^{54}$ Diario de Barcelona, 26.02.1834: 469. 
un innegable proceso de enriquecimiento personal que le había permitido situarse entre las principales fortunas de su ciudad natal. Cabe añadir, por otro lado, que en ese listado de los mayores contribuyentes de Barcelona, en 1835, aparecen al menos otros cinco individuos más que habían participado (o que acabarían participando) en el tráfico atlántico de esclavos: Carlos Torrents Miralda, Mariano Serra Soler, Juan Roig Jacas, Mariano Flaquer Dotres y Cristóbal Roig Vidal ${ }^{55}$.

\section{El patrimonio acumulado por Jaime Tintó Miralles}

Jaime Tintó Miralles falleció en Barcelona, en la primavera de 1839. Entre la documentación generada tras su defunción cabe destacar el inventario de los bienes que había dejado al morir. Un inventario que, en su caso, se limitó a recoger los apuntes propios de los balances de la firma Jaime Tintó e Hijo. Aquellos apuntes permiten conocer quiénes eran entonces sus principales corresponsables y en qué ciudades residían. Vale la pena remarcar, por ejemplo, los seis que vivían en Cuba. De hecho, del conjunto de ciudades portuarias del continente americano, Jaime Tintó parece haber mantenido una relación, hasta el día de su muerte, solamente con cuatro plazas mercantiles: con La Habana y con Matanzas, en la mayor de las Antillas (donde contaba con cuatro y con dos corresponsales, respectivamente), con San Juan (en Puerto Rico) y con Nueva Orleans (en los Estados Unidos), con un único corresponsal en cada plaza. En esta última ciudad de los Estados Unidos su hombre de confianza era su familiar y otrora capitán de buques negreros, el gaditano Juan Antonio Guerrero ${ }^{56}$.

En el testamento que Jaime Tintó otorgó poco antes de morir, el 12 de marzo de 1839 , daba cuenta de que su fortuna particular (representada única y exclusivamente por el capital invertido en su casa de comercio) se cifraba entonces en unos 45.500 pesos fuertes. Aquel peculiar inventario de los bienes dejados por el difunto Tintó, realizado por su hijo Antonio, ofrece interesante información respecto a los negocios que desarrolló en Barcelona, en la parte final de su vida. Sabemos así, por ejemplo, que a la altura de 1839 mantenía interés en el casco de cinco buques diferentes, por un importe total de 16.750 duros (equivalentes al $37 \%$ de su patrimonio). A falta de otras fuentes, el balance de la sociedad Jaime Tintó e Hijo, realizado el último día de 1838, así como algún otro documento público, vinculado también a la testamentaría de Tintó, nos ofrecen cierta información sobre las ganancias que pudo generar dicha empresa en los

\footnotetext{
${ }_{55}$ Diario de Barcelona, 24.10.1835: 2.400.

56 AHPB, Benito Lafont, manual de 1839 y 1840, 1839, fols. 164r-169v, 23.09.1839 y 172v-173v, 01.10.1839.
}

Hispania, 2021, vol. LXXXI, n. ${ }^{\circ}$ 267, enero-abril, págs. 73-100, ISSN: 0018-2141, e-ISSN: 1988-8368 https://doi.org/10.3989/hispania.2021.003 
años treinta. No parece que su rentabilidad neta haya sido especialmente destacada, al menos en el período transcurrido entre enero de 1830 y diciembre de 1832: en aquellos tres años la tasa media anual de ganancias de la sociedad Jaime Tintó e Hijo apenas se situó en el 3,75\% $\%^{57}$. Sabemos, por otro lado, que el último balance de dicha compañía (fechado en Barcelona el 31 de octubre de 1838) cifró su capital social en 45.500 duros o pesos fuertes. Si recordamos que nueve años antes, el 1 de enero de 1830, el capital que su socio principal, Jaime Tintó Miralles, tenía en dicha empresa ascendía a 31.373 duros, veremos cómo su incremento patrimonial en dicho período había sido de 14.127 pesos (o, lo que es lo mismo, del 45\%). Siendo así, en los nueve años transcurridos entre 1830 y 1838 la tasa media anual (no acumulativa) del incremento patrimonial registrado por la firma Jaime Tintó e Hijo debió situarse en el 5\%. Una tasa ciertamente remuneradora pero, en absoluto, espectacular.

La fortuna acumulada por Jaime Tintó debería haber sido mayor a la que realmente acabó dejando a sus herederos. Al fallecer, en 1839, coleaban todavía algunas deudas no cobradas de, al menos, una expedición a la costa africana. Me refiero a la que había realizado la goleta Semiramis diez años antes, en 1829. Pese a que los oficiales y marineros de aquella expedición supieron burlar la persecución de la armada británica y descargar los africanos esclavizados, en Cuba, Tintó nunca llegó a cobrar su parte del negocio: le seguían debiendo, en el momento de su muerte, 3.566 duros o pesos fuertes. Aunque el apunte contable no lo recoge explícitamente, es muy probable que el empresario moroso fuese el cántabro Joaquín Gómez. Es más, no hay que olvidar que, de todos sus corresponsales, aquel que le debía más dinero a Tintó, en el momento de su muerte, era precisamente Gómez, su socio en las expediciones negreras. Según otro apunte, extraído asimismo de los libros de contabilidad de Jaime Tintó e Hijo, su otrora socio Gómez le debía, todavía en 1839, 9.371 duros (una importante cantidad que superaba ampliamente la parte de interés de Tintó en cuatro buque diferentes: en las fragatas Fama y Artemisa, en el bergantín Amnistía y en el místico Tres Amigos). Esas dos abultadas deudas vendrían a confirmar la hipótesis que planteó, en su día, Enrique Sosa, según el cual, y más que por ningún otro factor,

57 Según su escritura fundacional, al joven Antonio Tintó Guzmán le correspondían un $25 \%$ de las ganancias generadas por la firma Jaime Tintó e Hijo. Teniendo en cuenta que dicho socio aportó 5.227 pesos como capital (el 1 de enero de 1830), y que dicha porción del caudal de la compañía creció hasta situarse en 6.258 pesos (el 31 de diciembre de 1832), resulta que los beneficios que acumuló el socio Antonio Tintó Guzmán en dicho período fueron de 1.031 pesos. Se deduce, por lo tanto, que los beneficios totales de la sociedad Jaime Tintó e Hijo en esos tres años debieron ser de 4.124 pesos. Si relacionamos dichas utilidades netas con el capital fundacional de la compañía (36.600 pesos), veremos cómo en tres años la tasa total de ganancias se situó en el 11,26\%. 
... los negreros inversionistas de Barcelona-Cádiz pudieron salir perjudicados por la catadura ética de Joaquín Gómez. [...]. El negocio que dirigió Tintó desde Barcelona, por acuerdo entre «caballeros negreros» fue un fracaso para ellos ${ }^{58}$.

No puedo compartir, sin embargo, la definición que propone dicho autor (quien habla literalmente de «fracaso») al analizar el resultado final de la participación de los negreros de Barcelona y de Cádiz en la trama empresarial liderada por el cántabro Joaquín Gómez, desde La Habana. Más acertado me parece entender que conductas como las descritas (en la relación Gómez-Tintó) estuvieron presentes en la trata ilegal de africanos esclavizados, a partir de 1820 , de manera que los beneficios de dicha actividad no siempre se repartieron en proporción al capital invertido. Hubo ciertamente comerciantes negreros sin ningún tipo de miramiento (como Joaquín Gómez) que consiguieron aumentar aún más su fortuna, a costa de sus perjudicados socios. De aquella manera, Tintó acabaría recibiendo, en Barcelona, menos caudales de los que debería haber percibido, en función del capital invertido y de las ganancias realmente generadas por las expediciones. Aun así, lejos de considerar su dedicación a la trata como un fracaso cabría valorarla como un exitoso camino hacia el enriquecimiento personal y familiar, así como también una vía de ascenso social. Dos procesos paralelos que se aprecian singularmente al analizar las trayectorias de los miembros de la siguiente generación.

\section{El empresario Antonio Tintó Guzmán}

El único hijo varón de Jaime Tintó Miralles fue Antonio Tintó Guzmán, quien naciera en Cádiz en marzo de 1810. Como antes señalé, al crear, en 1830, la firma Jaime Tintó e Hijo, su padre le quiso incorporar como socio a pesar de no haber alcanzado todavía la mayoría de edad civil. Antonio Tintó principió entonces una notable carrera empresarial, desarrollada inicialmente bajo la larga sombra de su padre y vinculada al ilegal comercio de africanos esclavizados. Es más, al anular la sociedad Jaime Tintó e Hijo, en marzo de 1833, su socio principal optó por no hacer pública tal disolución pensando precisamente en el futuro de su hijo Antonio. Según consignara en su último testamento: «El motivo de no haber dado publicidad a la disolución de la sociedad de mi hijo fue solamente con el fin de que mi hijo tuviere después de mis días las relaciones necesarias para en caso de querer continuar el comercio, no se viese en el caso de tener que crearlas». Padre e hijo acordaron entonces mantener la sociedad familiar de facto, aunque no de iure.

\footnotetext{
58 SOSA, 1998: 131.
}

Hispania, 2021, vol. LXXXI, n. ${ }^{\circ}$ 267, enero-abril, págs. 73-100, ISSN: 0018-2141, e-ISSN: 1988-8368 
Cuando el joven Antonio Tintó Guzmán se casó con Ana Francovich, el 25 de junio de 1834, su padre le dio los 5.227 pesos fuertes a que había ascendido su hijuela, de la herencia materna. Y aunque, en un primer momento, Antonio Tintó y su esposa intentaron vivir en una casa propia, lo cierto es que apenas cinco meses después de haberse casado, en noviembre de 1834, el joven matrimonio regresó al hogar de Jaime Tintó Miralles, sito en el número 75 de la calle Escudellers Blancs. El patriarca Tintó no sólo les cedió una parte de su vivienda, sino que les regaló, además, todo el mobiliario ${ }^{59}$. Y cuando Jaime Tintó Miralles redactó su último testamento, en marzo de 1839, optó precisamente por otorgar a su único hijo varón (y socio), Antonio Tintó Guzmán, la condición de «albacea absoluto, liquidador y tenedor de [sus] bienes» ${ }^{60}$. Al joven Antonio Tintó le tocó así repartir el caudal hereditario dejado por su padre entre sus tres hermanas. Este reparto se hizo de forma igualitaria, por voluntad del difunto. La única de las hijas de Jaime Tintó Miralles que había muerto antes que él era la mayor, Julia, la cual había fallecido en la cubana ciudad de Matanzas, siendo viuda del comerciante Benjamin Manuel Booth (cuya quiebra sufrió, por cierto, su suegro Jaime Tintó). El matrimonio Booth-Tintó había tenido cuatro hijos y dos hijas, quienes acabaron repartiéndose la hijuela correspondiente a su difunta madre. Al menos dos de aquellas hijas (Julia y Manuela Booth Tintó) vivían entonces, por cierto, en Barcelona. También las otras dos hijas de Jaime Tintó Miralles, las hermanas Josefa y Ana Tintó Guzmán, residían entonces en la capital catalana. La primera se había casado con el militar menorquín Sebastián Crell mientras que la pequeña había hecho lo propio con el notario Luis Ferrer $^{61}$. No cabe duda de que la trayectoria personal y empresarial de Jaime Tintó Miralles (a todas luces un verdadero self-made man) había permitido a sus cuatro hijos, es decir, a los miembros de la siguiente generación, convenir enlaces matrimoniales acordes con su estatus, o sea, con un estatus superior al que habían tenido sus propios padres a su misma edad.

En el caso de Antonio Tintó Guzmán, su capacidad para desarrollar una intensa actividad como hombre de negocios (así como sus inversiones en diferentes compañías) deben explicarse gracias a la fortuna que pudo heredar de sus padres y al capital acumulado por él mismo por su participación en la casa Jaime Tintó e Hijo. A los cuatro años de la muerte de su padre, el 28 de enero de 1843, Antonio Tintó fue uno de los seis socios fundadores de una sociedad que se creó entonces para la construcción de la carretera que debía unir las capitales de Lleida y de Tarragona, una firma cuyo capital era de 625.000 pesetas (de los cuales él aportó 125.000 pesetas). Compartió aquel negocio con

\footnotetext{
59 AHPB, Benito Lafont, manual de 1833 y 1834, año 1834, fols. 171r-172v, 29.11.1834.

${ }^{60}$ AHPB, Escribanía de Marina, J. M. Planas Compte, manual de 1839, 28.09.1839, fols, 588r-588v; y 09.10.1839, fols. 616r-620v.

${ }^{61}$ AHPB, Benito Lafont, manual de 1839 y 1849, 1839, fols. 110v-119r, 16.07.1839.
} 
individuos como Jaime Safont Lluch, integrante de la familia que acabaría comprando más bienes territoriales en toda España merced a la desamortización de Mendizábal. Exactamente aquel mismo día Antonio Tintó firmó la escritura de constitución de la nueva Sociedad Catalana para el Alumbrado por Gas (precedente directo de la actual Naturgy, una firma del IBEX35), secundando una iniciativa impulsada por Charles Lebon y financiada por el banquero Pedro Gil Babot (quién años atrás también había participado, por cierto, en el tráfico de esclavos hacia Cuba). Antonio Tintó fue, así, uno de los siete únicos socios fundadores de dicha firma gasista. Es más, su interés por aquel novedoso sector le llevó a incorporarse, en octubre de 1844, como socio de la empresa impulsada por el propio Charles Lebon y por Jules Lecoq para la explotación del alumbrado por gas en la ciudad de Valencia. Por otro lado, el propio Antonio Tintó decidió financiar, en abril de 1845, la iniciativa de Cayetano Ciccarelli, quién había obtenido siete meses atrás la concesión para limpiar el puerto de Barcelona ${ }^{62}$.

La conducta inversora de Antonio Tintó Guzmán en los años cuarenta revela que había orientado una parte de su actividad empresarial hacia el ámbito de las obras públicas y de los servicios municipales. Por esa razón, fue precisamente su sociedad Jordá Tintó y Cía. la empresa encargada de construir un edificio que acabaría convirtiéndose en uno de los principales símbolos de Barcelona y en uno de los principales espacios de sociabilidad de la burguesía catalana. Me refiero al Gran Teatro del Liceo.

Interesada en dotar a Barcelona de «un grande y magnífico teatro capaz de contener a lo menos 3.500 espectadores», la sociedad Liceo Filarmónico Dramático Barcelonés de S. M. la Reyna D. ${ }^{a}$ Isabel II consiguió comprar, en la primavera de 1844, el antiguo convento desamortizado de los Trinitarios. Dicha sociedad, cuyo principal motor era Joaquín de Gispert y de Anglí, hizo un rápido llamamiento a sus socios, y a otros particulares, a quienes pidió que aportasen los fondos precisos para construir aquel magno teatro. Un llamamiento que no tuvo, sin embargo, el éxito esperado: la sociedad del Liceo no fue capaz de reunir el caudal necesario «para una obra de tal magnitud». Joaquín de Gispert se vio obligado, entonces, a proponer a la firma Jordá Tintó y Cía. que se encargase del derribo del viejo convento y de la construcción del nuevo teatro, financiando todas las obras a sus expensas. Así lo acordaron el 27 de noviembre de 1844. Aquel día, Antonio Tintó Guzmán y su socio José Jordá se comprometieron a realizar las obras necesarias para levantar aquel magnífico teatro, por orden y en nombre de la sociedad del Liceo, en un plazo inferior

${ }^{62}$ AHPB, José Manuel Planas Compte, 28.01.1843; Juan Prats, manual de 1843, fols. 39r-41v, 28.01.1843, manual de 1844, fols. 186r-188r, 30.10 .1844 (Tintó aporta 5.000 pesos fuertes) y Manual de 1845, fols. 189r-191v, 05.04.1845: «Empresa de la limpieza del puerto de esta ciudad».

Hispania, 2021, vol. LXXXI, n. ${ }^{\circ}$ 267, enero-abril, págs. 73-100, ISSN: 0018-2141, e-ISSN: 1988-8368 https://doi.org/10.3989/hispania.2021.003 
a dos años y con arreglo a los planos que les facilitase dicha entidad. A cambio, la sociedad del Liceo cedió aquel mismo día «a los mismos Sres. Jordà Tintó y Compañía y a sus derecho habientes siete décimas sextas partes de la totalidad de palcos y lunetas que contendrá el nuevo teatro, deducidos solamente de ella dos palcos que deben reservarse, el uno para las autoridades y el otro para la Junta Directiva del Liceo» ${ }^{63}$. En otras palabras, aquella firma impulsada y participada por el otrora comerciante negrero Antonio Tintó Guzmán no sólo fue la empresa responsable de la construcción del Gran Teatro del Liceo, inaugurado finalmente en abril de 1847 , sino que se quedó, además, con casi la mitad de sus palcos.

Mientras tanto, Antonio Tintó participó en la creación de otra empresa, fundada en Barcelona en septiembre de 1846, y que se llamó Agrícola Catalana. Seis años después, en 1852, tomó parte en otras dos empresas más: por un lado, en julio de aquel año, contribuyó con 3.000 pesetas a la recién creada sociedad José Casadesús y Cía., una firma dedicada a la fabricación de ladrillos, y, por otro lado, tres meses después, en septiembre de 1852, participó en la fundación de la Compañía del Ferrocarril de Barcelona a Zaragoza, suscribiendo 100 acciones. Tintó participó también del boom asegurador que registró la capital catalana en 1856, impulsando, en marzo de aquel año, una nueva firma llamada La Aseguradora. Y dos años después, en junio de 1858, intervino en la creación de una sociedad minera llamada Asfalto Natural Ampurdanés, cuyo objeto era la explotación de dos minas de asfalto en el término municipal de Llers, cerca de Figueres ${ }^{64}$. No pretendo resumir aquí la trayectoria empresarial o inversora desarrollada por Antonio Tintó Guzmán pero sí poner de relieve que acabó desarrollando una notable carrera como hombre de negocios y, sobre todo, que dicha carrera no hubiera sido posible sin su condición de hijo, socio y heredero de Jaime Tintó Miralles.

\section{Conclusiones}

El ejemplo de los Tintó, padre e hijo, revela un fenómeno cuyo alcance va más allá de este estudio de caso: la participación directa en el comercio de africanos esclavizados permitió a un número indeterminado de individuos conocer

${ }^{63}$ AHPB, F. J. Moreu, manual de 1844, 27.11.1844, fols. 338v-342r. Véase también AHPB, J. M. Planas Compte, manual de 1844, 27.11.1844, fols. 422v-425r.

${ }^{64}$ AHPB, Magín Soler Gelada, manual de 1846, fols. 236r-238v, 23.09.1846; J. M. Planas Compte, manual de 1852, 2. parte, fols. 7r-10v, 03.07.1852; José Falp, manual de 1852, fols. 239-360v. 26.09.1852; J. M. Planas Compte, manual de 1856, 1. ${ }^{\mathrm{a}}$ parte, fols. $160 \mathrm{v}-177 \mathrm{v}$. 17.03.1856 y Manual de 1856, 2. ${ }^{\text {a }}$ parte, fols. 100v-105v, 17.08.1856; Fernando Moragas Ubach, manual de 1858,2 . ${ }^{\text {parte, fols. } 12.06 .1858 .}$ 
un claro proceso de enriquecimiento personal y de ascenso en el escalafón social. En la Cataluña del siglo XIX hubo, por ejemplo, numerosos capitanes de buques negreros que acabaron convirtiéndose en ricos y dinámicos empresarios $^{65}$. Sabemos que en diversas ocasiones, como en el caso de los Tintó, aquel proceso de enriquecimiento y de ascenso social resultó apreciable no solamente en la primera generación sino también en la siguiente. La participación en el comercio ilegal de africanos esclavizados durante el siglo XIX fue, sin duda, una actividad que permitió a diferentes sagas familiares aumentar tanto su riqueza como su patrimonio y facilitar, así, su inserción en el seno de la heterogénea burguesía catalana del siglo XIX.

Una investigación de José Miguel Sanjuán sobre la élite barcelonesa entre 1714 y 1919 demuestra, por otro lado, la gran importancia que tuvieron los indianos en el conjunto de esa burguesía catalana de la que hablo. Dicho autor afirma que el impacto de aquellos peculiares empresarios en «la economía catalana fue muy relevante, tanto por el papel que jugaron dirigiendo grandes inversiones como por el capital humano que aportaron a la nueva élite catalana formada tras la Guerra» de la Independencia. Y añade que, durante el siglo XIX, «las Antillas [españolas] supusieron durante varias décadas un lugar donde la posibilidad de acumular capitales se disparó» ${ }^{66}$. Aunque no todos aquellos indianos de la Barcelona decimonónica estuvieron implicados en el comercio de esclavos, hubo un buen número que sí que participaron. Podemos señalar los ejemplos de Cristóbal Roig y Vidal, Juan Roig Jacas, Mariano Flaquer, Isidro Inglada, Esteban Gatell, José Carbó y Antonio López, entre muchos otros. Dibujar, en detalle, sus respectivas trayectorias vitales, como acabo de hacer con Jaime Tintó, ayuda a conocer mejor tanto el fenómeno de la participación catalana en el comercio de esclavos como el origen de un importante sector de la burguesía barcelonesa durante el siglo XIX.

\section{Bibliografía}

Cózar Navarro, María del Carmen, La orca del Atlántico. Pedro Martínez y su clan en la trata de esclavos (1817-1867), Madrid, Silex, 2021.

Eltis, David y Felipe-González, Jorge, «The Rise and Fall of the Cuban Slave Trade. New Data, new Paradigms», Alex Borucki, David Eltis y David Wheat, From the Galleons to the Highlands. Slave Trade Routes in the Spanish Americas, Albuquerque, University of New Mexico Press, 2020: 201-222.

Fernández Prieto, Leida, «Plantas y saberes en la red del tráfico negrero: CubaEspaña-África», Martín Rodrigo y M. del Carmen Cózar (eds.), Cádiz y el tráfico de esclavos. De la legalidad a la clandestinidad, Madrid, Silex, 2018: 295-321.

\footnotetext{
${ }^{65}$ RODRIGO, 2017.

${ }^{66}$ SANJUAN, 2018.
}

Hispania, 2021, vol. LXXXI, n. ${ }^{\circ}$ 267, enero-abril, págs. 73-100, ISSN: 0018-2141, e-ISSN: 1988-8368 
Fradera Barceló, Josep Maria, «La participació catalana en el tràfic d'esclaus (17891845)», Recerques, 16 (Barcelona, 1984): 119-139.

House of Commons Parliamentary Papers, Slave Trade, Class A. Correspondence with the British Commissioners at Sierra Leone, The Havannah, Rio de Janeiro and Surinam relating to Slave Trade, 1824-1825, Londres, 1825.

Law, Robin, Ouidah. The Social History of a West African Slaving Port, 1727-1892, Columbus, Ohio State University Press, 2004.

Maluquer de Motes, Jordi, «La burgesia catalana i l'esclavitud colonial: modes de producció i pràctica política», Recerques, 3 (Barcelona, 1974): 83-136.

Moreno Fraginals, Manuel, El Ingenio. Complejo económico social cubano del azúcar, La Habana, Editorial de Ciencias Sociales, 1978 [edición original de 1964].

Nerín Abad, Gustau, Traficants d'ànimes. Els negrers espanyols a l’África, Barcelona, Pòrtic, 2015.

Relación del viaje de Marcelino Andrés por las costas de África, Cuba e Isla de Santa Elena (1830-1832) publicado ahora por vez primera por el P. Agustín Jesús Barreiro (agustino), Madrid, Sociedad Geográfica Nacional, 1933.

Rodrigo y Alharilla, Martín, Los marqueses de Comillas, 1817-1925. Antonio y Claudio López, Madrid, LID, 2000.

Rodrigo y Alharilla, Martín, «Cuatro capitanes negreros catalanes en tiempos de la trata ilegal: José Carbó, Pedro Manegat, Gaspar Roig y Esteban Gatell», Martín Rodrigo y Lizbeth Chaviano (eds.), Negreros y esclavos. Barcelona y la esclavitud atlántica (ss. XVI-XIX), Barcelona, Icaria, 2017: 101-130.

Rodrigo y Alharilla, Martín y Chaviano Pérez, Lizbeth J. (eds.), Negreros y esclavos. Barcelona y la esclavitud atlántica (ss. XVI-XIX), Barcelona, Icaria, 2017.

Rovira i Fors, Josep, «El bergantí negrer Tellus», L'Avenç, 75 (Barcelona, 1984): 52-55.

Ruiz de Gordejuela, Jesús, «Retorno de los comerciantes españoles tras la independencia de México», Temas Americanistas, 37 (Sevilla, 2016a): 217-240.

Ruiz de Gordejuela, Jesús, «Remesas de caudales españoles durante los primeros años del México independiente, 1821-1827», Revista Complutense de Historia de América, 42 (2016b): 293-317.

Sanjuan Marroquín, José Miguel, Las élites económicas barcelonesas, 1714-1919, tesis doctoral, Universidad de Barcelona, 2018.

Solà i Parera, Àngels, «La independencia mexicana y la salida de capitales de españoles residentes en México (1810-1830)», en Manuel González Portilla, Jordi Maluquer de Motes y Borja de Riquer (eds.), Industrialización y nacionalismo, Barcelona, Universitat Autònoma de Barcelona, 1985: 339-353.

Soler, Raimon, Emigrar per negociar. L'emigració des de la Comarca de Garraf: el cas de Gregori Ferrer i Soler, 1791-1853, Vilanova i la Geltrú, El Cep i la Nansa, 2002.

Sosa Rodríguez, Enrique, Catalanes y gaditanos en la trata negrera cubana, 18271833, La Habana, Fundación Fernando Ortiz, 1998.

Sust Fatjó, Xavier, «La captura de la goleta Matilde comandada pel capità vilassarenc Pere Mas Roig, (a) “El Pigat”. Any 1837», Singladures, 33 (Vilassar de Mar, 2016): $9-34$ 
Virella i Bloda, Albert, L'aventura ultramarina de la gent de Vilanova i la nissaga dels Samà, Vilafranca del Penedès, Museu de Vilafranca, 1990.

Zeuske, Michael, «Capitanes y comerciantes catalanes de esclavos», Martín Rodrigo y Lizbeth Chaviano (eds.), Negreros y esclavos. Barcelona y la esclavitud atlántica (ss. XVI-XIX), Barcelona, Icaria, 2017: 63-100.

Recibido: 24/04/2019

Aceptado: 08/06/2020 